\title{
High-resolution metabolomics determines the mode of onset of type 2 diabetes in a 3-year prospective cohort study
}

\author{
YESEUNG LEE $^{1 *}$, ARYO DIMAS PAMUNGKAS ${ }^{1 *}$, CARL ANGELO D. MEDRIANO $^{1}$, \\ JINSUNG PARK ${ }^{2}$, SERI HONG ${ }^{3}$, SUN HA JEE $^{3}$ and YOUNGJA H. PARK ${ }^{1}$ \\ ${ }^{1}$ Metabolomics Laboratory, College of Pharmacy, ${ }^{2}$ Department of Control and Instrumentation on Engineering, \\ Korea University, Sejong City 30019; ${ }^{3}$ Department of Epidemiology and Health Promotion and Institute for Health Promotion, \\ Graduate School of Public Health, Yonsei University, Seoul 03722, Republic of Korea
}

Received September 14, 2017; Accepted November 7, 2017

DOI: 10.3892/ijmm.2017.3275

\begin{abstract}
Type 2 diabetes mellitus(DM) is a progressive disease and the rate of progression from non-diabetes to DM varies considerably between individuals, ranging from a few months to many years. It is important to understand the mechanisms underlying the progression of diabetes. In the present study, a high-resolution metabolomics (HRM) analysis was performed to detect potential biomarkers and pathways regulating the mode of onset by comparing subjects who developed and did not develop type $2 \mathrm{DM}$ at the second year in a 3-year prospective cohort study. Metabolic profiles correlated with progression to DM were examined. The subjects $(n=98)$ were classified into four groups: Control (did not develop DM for 3 years), DM (diagnosed with DM at the start of the study), DM onset at the third year and DM onset at the second year. The focus was on the comparison of serum samples of the DM groups with onset at the second and third year from the first year, where these two groups had not developed DM, yet. Analyses involved sample examination using liquid chromatography-mass spectrometry-based HRM and multivariate statistical analysis of the data. Metabolic differences were identified across all analyses with the affected pathways involved in metabolism associated with steroid biosynthesis and bile acid biosynthesis. In the first year, higher levels of cholesterol \{mass-to charge ratio $\left.(\mathrm{m} / \mathrm{z}) 369.35,\left(\mathrm{M}+\mathrm{H}-\mathrm{H}_{2} \mathrm{O}\right)^{+}\right\}, 25$-hydroxycholesterol $\left[\mathrm{m} / \mathrm{z} 403.36,(\mathrm{M}+\mathrm{H})^{+}\right], 3 \alpha, 7 \alpha$-dihydroxy-5 $\beta$-cholestane [m/z 443.33, $\left.(\mathrm{M}+\mathrm{K})^{+}\right], 4 \alpha$-methylzymosterol-4-carboxylate $\left[\mathrm{m} / \mathrm{z} 425.34,\left(\mathrm{M}+\mathrm{H}_{-} \mathrm{H}_{2} \mathrm{O}\right)^{+}\right]$, and lower levels of 24,25-dihydrolanosterol $\left[\mathrm{m} / \mathrm{z} 429.40,(\mathrm{M}+\mathrm{H})^{+}\right]$were evident in the group with $\mathrm{DM}$ onset at the second year compared with those in the group
\end{abstract}

Correspondence to: Professor Youngja H. Park, Metabolomics Laboratory, College of Pharmacy, Korea University, Sejong City 30019, Republic of Korea

E-mail: yjhwang@korea.ac.kr

*Contributed equally

Key words: liquid chromatography-mass spectrometry, type 2 diabetes, metabolomics, cholesterol with DM onset at the third year. These results, with a focus on the cholesterol biosynthesis pathway, point to important aspects in the development of DM and may aid in the development of more effective means of treatment and prevention.

\section{Introduction}

Type 2 diabetes mellitus (DM) is characterized by an increase in glucose levels or hyperglycemia due to pancreatic cell dysfunction and insulin resistance $(1,2)$. In 2011, the prevalence of DM in Koreans aged 20-79 years was 7.5\% (adjusted to world population). The prevalence is estimated to increase to $8.7 \%$ by 2030 (3). Since DM is a multifactorial disease influenced by genetic as well as environmental risk factors (4), the exact etiology of DM remains elusive $(5,6)$. Furthermore, the rate of progression varies markedly between individuals (7) and little is known about the mode of onset. It is important to understand the mechanisms or biomarkers that are associated with the rapid progression of diabetes. Delaying the onset of DM may specifically improve therapies and understanding the characteristics of those who progress slowly may aid in the management of patients with DM (8).

Recent technologies, including high-resolution metabolomics (HRM), have enabled the discovery of potential biomarkers that may be beneficial for the diagnosis, management and treatment of various diseases (9-11). HRM generates comprehensive metabolic profiles by simultaneously measuring thousands of low-molecular weight metabolites in biological fluids, cells and tissues associated with certain diseases (12-14). The sensitivity and selectivity of HRM are best suited to the analysis of highly complex metabolite mixtures, such as biological extracts. HRM may also be used for the identification of potentially affected metabolites and pathways with the aid of the metabolite databases and in human metabolic pathway analyses, such as the Kyoto Encyclopedia of Genes and Genomes (KEGG) (15).

Metabolic profiling allows for the exploration of different types of metabolites that may be affected by the progression or development of diabetes (16). Various metabolites have been correlated with insulin resistance and diabetes prediction in studies that mainly focused on a general comparison of control and case groups of DM during follow-up (17-21). A recent 
study from India reported that $45.1 \%$ of subjects with normal glucose tolerance developed dysglycemia. Various predictors of progression included advancing age, family history of diabetes and cholesterol levels (22). Thus, when performing metabolomics analyses, differences in the onset of DM among subjects must be taken into account, and an inter-patient variability in the affected metabolites is likely. The present study used HRM to detect low-molecular weight metabolites by comparing samples collected from subjects who subsequently developed DM. The aim was to identify factors associated with the mode of onset of DM even prior to the development of symptoms.

\section{Materials and methods}

Materials. Liquid chromatography-mass spectrometry (LC-MS) grade water (Tedia, Fairfield, OH, USA), acetonitrile (Burdick \& Jackson, Muskegon, MI, USA) and formic acid (Fluka, St. Louis, MO, USA) were used as the mobile phase. For quality control, three isotopes were used: Caffeine $\left(3-\right.$ methyl $\left.-{ }^{13} \mathrm{C}\right)$, L-methionine $\left({ }^{13} \mathrm{C}_{5},{ }^{15} \mathrm{~N}\right)$ and $\mathrm{N}, \mathrm{N}$-diethyl-M-toluamide (Cambridge Isotope Laboratories, Inc., Tewksbury, MA, USA).

Human participants. This pilot study was reviewed and approved by the Korea University Institutional Review Board (Sejong City, Korea) and conformed to the board's ethical guidelines (no. KU-IRB-15-19-A-1). Written informed consent was obtained from all participants. The subjects were from the Korean Cancer Prevention Study (KCPS-II Biobank), a pool of 159,844 participants who voluntarily underwent private health examinations and had provided informed consent in one of 11 centers located in Seoul and Gyeonggi provinces in South Korea from 2004 to 2013. Among all participants (age, 30-60 years) were selected. Those with missing data on essential or metabolic syndrome-associated variables were excluded.

The included participants with or without type 2 DM were classified into four groups based on fasting blood sugar levels, with serum samples collected in a span of 3 years. ${ }^{\text {G1 }} \mathrm{NNN}$ was the negative control group comprising non-diabetic (NDM) patients for the 3-year cohort study. ${ }^{\mathrm{G} 2} \mathrm{DDD}$ represented the positive control group comprising individuals who already

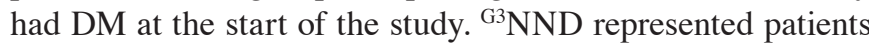
who developed DM in the third year and ${ }^{\mathrm{G} 4} \mathrm{NDD}$ represented patients who developed DM in the second year (Fig. 1A). Type 2 DM was defined as fasting blood sugar levels of $>125 \mathrm{mg} / \mathrm{dl}$ (Fig. 1B). The subjects' full demographics in the first year (baseline) are provided in Table I. Measurements of the body mass index (BMI) and fasting blood sugar were performed by utilizing COBAS INTEGRA 800 and 7600 Analyzers (Hitachi, Tokyo, Japan) (23). Data were analyzed for significance using SPSS ${ }^{\circledR} 24$ statistical software (IBM Corp., Armonk, NY, USA).

$L C$-MS. The samples (50- $\mu 1$ aliquots) were diluted with $200 \mu \mathrm{l}$ acetonitrile and centrifuged at 14,000 x g for $5 \mathrm{~min}$ at $4^{\circ} \mathrm{C}$ to remove any protein (24). The samples were then randomized and analyzed using ultra performance LC (C18 Synchronis aQ, $1.9 \mu \mathrm{m}, 100 \times 2.1 \mathrm{~mm}$; Thermo Fisher Scientific, Inc., Waltham, MA, USA) coupled with a quantitative time-of-flight MS using a model 6550 apparatus (Agilent
Technologies, Santa Clara, CA, USA). The mobile phases were water and acetonitrile, and contained $0.1 \%$ formic acid. LC was run using the following gradient program: $95 \%$ water for $1 \mathrm{~min}$, a linear decrease to $55 \%$ water over $8 \mathrm{~min}$, a descending gradient to $10 \%$ water over $3 \mathrm{~min}$, a 1.5 -min hold and return to $95 \%$ water over $0.1 \mathrm{~min}$. Detection of the mass/ charge ratio $(\mathrm{m} / \mathrm{z})$ of ions set from 50 to 1,000 with a resolution of 20,000 over $15 \mathrm{~min}$, LC runs with data extraction using the apLCMS algorithm provided a minimum of 6,000 reproducible features, with the mass accuracy being sufficient to allow for the prediction of the elemental composition in numerous instances.

Statistical analyses for metabolic profiling. After processing the data using apLCMS (25), all of the features of the samples were retrieved. The features from the LC-MS analyses were $\log _{2}$ transformed and quantile normalized prior to applying bioinformatics. Statistical analysis was performed on the extracted data using MetaboAnalyst 3.0 (http://www.metaboanalyst.ca/) for additional statistical tests, including principal component analysis (PCA), orthogonal signal correction/partial least squares-discriminant analysis (OPLS-DA), hierarchical cluster analysis (HCA) and Manhattan plot, to specifically differentiate between the profiles of all four categories in one analysis. Feature intensities were first log-transformed and auto-scaled prior to the performance of PCA and OPLS-DA with a confidence level of $95 \%$. Statistical analyses, which included univariate analysis, Manhattan plot and false discovery rate adjusted P-value (FDR) (26), were performed to determine the metabolites that were significantly different between ${ }^{\mathrm{G} 3} \mathrm{NND}$ and ${ }^{\mathrm{G} 4} \mathrm{NDD}$ in the first year. The metabolic profiles were differentiated using Limma 2-HCA to distinguish between the two groups based on their metabolites (27).

Scheme of analysis. Utilizing samples from all 3 years, all groups were analyzed by multivariate analysis to discern metabolic differences. The present study focused on exploring the difference in metabolic profiles in the first year between ${ }^{\mathrm{G} 3} \mathrm{NND}$ and ${ }^{\mathrm{G} 4} \mathrm{NDD}$, where the two groups were initially NDM but subsequently developed DM in the prospective cohort. Thus, a Manhattan plot and HCA were used to examine ${ }^{\mathrm{G} 3} \mathrm{NND}$ and ${ }^{\mathrm{G} 4} \mathrm{NDD}$ in the first year, looking for potential discriminating metabolites concerning diabetes progression. In addition, it was examined whether the metabolic changes were similar in the ${ }^{\mathrm{G} 3} \mathrm{NND}$ and ${ }^{\mathrm{G} 4} \mathrm{NDD}$ groups in the second and third year compared with those in the first year.

Annotation using METLIN and KEGG metabolic pathway analysis. An $\mathrm{m} / \mathrm{z}$ feature is defined by $\mathrm{m} / \mathrm{z}$, ion intensity and retention time. The $\mathrm{m} / \mathrm{z}$ values were annotated using the METLIN Mass Spectrometry Database (https://metlin.scripps.edu) to identify the metabolites (28). Annotated features from the METLIN database are mapped on human metabolic pathways using the KEGG database. The human metabolic pathways of the KEGG database (http://www.genome.jp/kegg/tool/map_pathway2.html) were used for mapping the significant features from the Manhattan plot with an FDR of $q=0.05$. The matched features were displayed as black dots in the pathway maps to determine which pathways were affected by each case condition. 
Table I. Demographics of subjects during the first year.

\begin{tabular}{|c|c|c|c|c|}
\hline Characteristic & $\begin{array}{l}{ }^{\mathrm{G} 1} \mathrm{NNN} \\
(\mathrm{n}=24)\end{array}$ & $\begin{array}{l}{ }^{\mathrm{G}} \mathrm{DDD} \\
(\mathrm{n}=24)\end{array}$ & $\begin{array}{l}{ }^{\mathrm{G}} \text { NND } \\
(\mathrm{n}=25)\end{array}$ & $\begin{array}{l}{ }^{\mathrm{G} 4} \mathrm{NDD} \\
(\mathrm{n}=25)\end{array}$ \\
\hline $\operatorname{Sex} M / F(n)$ & $19 / 5$ & $20 / 4$ & $20 / 5$ & $22 / 3$ \\
\hline Age (year) & $39.29 \pm 7.33$ & $45.13 \pm 7.01^{\mathrm{a}}$ & $43.36 \pm 6.43$ & $44.44 \pm 7.15$ \\
\hline BMI $\left(\mathrm{kg} / \mathrm{m}^{2}\right)$ & $24.13 \pm 2.67$ & $26.41 \pm 3.56$ & $25.71 \pm 2.89$ & $25.18 \pm 3.12$ \\
\hline Fasting blood sugar (mg/dl) & $87.79 \pm 10.27$ & $165.42 \pm 43.26^{\mathrm{a}}$ & $104.8 \pm 11.38^{\mathrm{b}}$ & $103.76 \pm 12.7^{b}$ \\
\hline Total cholesterol (mg/dl) & $204.88 \pm 36.09$ & $210.21 \pm 35.17$ & $198.12 \pm 20.7$ & $194.68 \pm 31.9$ \\
\hline Triglycerides (mg/dl) & $149.33 \pm 71.53$ & $215.17 \pm 138.3$ & $194.04 \pm 125.59$ & $183.36 \pm 107.36$ \\
\hline High-density lipoproteins (mg/dl) & $48.16 \pm 8.18$ & $45.44 \pm 9.18$ & $49.00 \pm 4.03$ & $48.6 \pm 5.94$ \\
\hline Low-density lipoproteins (mg/dl) & $128.73 \pm 37.72$ & $131.37 \pm 37.57$ & $114.30 \pm 22.51$ & $111.86 \pm 37.22$ \\
\hline Systolic blood pressure (mmHg) & $118.88 \pm 13.06$ & $125.58 \pm 14.65$ & $121.08 \pm 16.9$ & $119.32 \pm 15.34$ \\
\hline Diastolic blood pressure (mmHg) & $74.29 \pm 10.24$ & $79.54 \pm 8.86$ & $76.72 \pm 11.22$ & $78.64 \pm 10.36$ \\
\hline
\end{tabular}

Values are expressed as the mean \pm standard deviation. ${ }^{\mathrm{a}} \mathrm{P}<0.05 \mathrm{vs} .{ }^{\mathrm{G} 1} \mathrm{NNN}$; and ${ }^{\mathrm{b}} \mathrm{P}<0.05 \mathrm{vs}$. ${ }^{\mathrm{G} 2} \mathrm{DDD}$, based on analysis of variance with Tukey's post hoc test. Groups: ${ }^{\mathrm{G} 1} \mathrm{NNN}$, control group (patients without DM); ${ }^{\mathrm{G} 2} \mathrm{DDD}-1$, sample from the first year of patients with DM from the beginning of study; ${ }^{\mathrm{G} 3} \mathrm{NND}$, patients that progressed to DM at the third year; ${ }^{\mathrm{G} 4} \mathrm{NDD}$, patients that progressed to DM at the second year. DM, diabetes mellitus; M, male; F, female; BMI, body mass index.
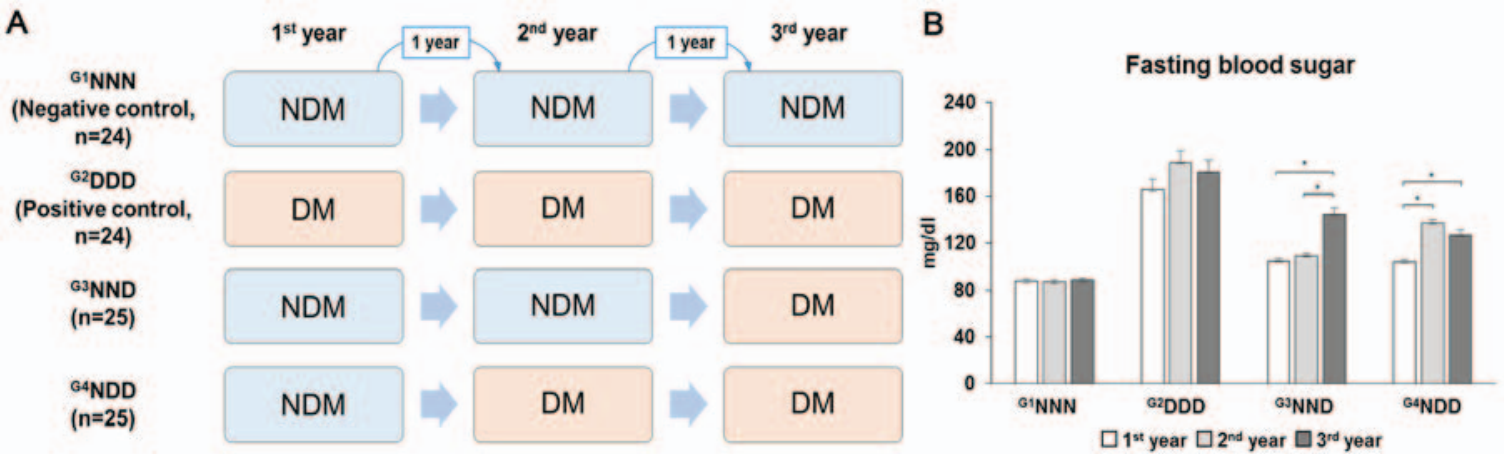

Figure 1. Experimental design to determine the mode of onset of DM. (A) Design of groups in the 3-year prospective cohort study. (B) Alteration of the levels of fasting blood sugar in the 3 years in all groups. Groups: ${ }^{\mathrm{Gl}} \mathrm{NNN}$, control group (patients without DM); ${ }^{\mathrm{G} 2} \mathrm{DDD}$, patients with DM from the beginning of study; ${ }^{\mathrm{G}} \mathrm{NND}$, patients that progressed to $\mathrm{DM}$ at the third year; ${ }^{\mathrm{G}} \mathrm{NDD}$, patients that progressed to DM at the second year. ${ }^{*}<0.05$. DM, diabetes mellitus; NDM, no DM.

\section{Results}

Statistical and group comparison. The four group categories were first analyzed using the unsupervised, multivariate statistical PCA procedure to determine whether any metabolic differences were present. PCA did not provide a good separation of the four groups (Fig. 2A). HCA exhibited a tendency to separate subjects into four groups based on auto-scaled and log-transformed features (Fig. 2B). In addition, supervised OPLS-DA was then used to analyze the data. As displayed in Fig. 2C, a score plot was generated to illustrate the metabolic differences throughout the four stages of DM acquisition. This OPLS-DA model demonstrated a clear separation of groups with an $\mathrm{R}^{2}$ value of goodness of fit of 0.956 and a $\mathrm{Q}^{2}$ value of predictive ability of the model of 0.835 . A clear separation was expected to be evident between ${ }^{\mathrm{G} 1} \mathrm{NNN},{ }^{\mathrm{G} 2} \mathrm{DDD},{ }^{\mathrm{G} 3} \mathrm{NND}$ and ${ }^{\mathrm{G} 4} \mathrm{NDD}$, indicating that groups could be distinguished based on certain serum metabolites in their metabolic profiles. Further analyses focused on the comparison between ${ }^{\mathrm{G} 3} \mathrm{NND}$ and ${ }^{\mathrm{G} 4} \mathrm{NDD}$ in order to observe the effect of a different onset of DM on the metabolic profile.
A good separation between ${ }^{\mathrm{G} 3} \mathrm{NND}$ and ${ }^{\mathrm{G} 4} \mathrm{NDD}$ was clearly observed for each year on the OPLS-DA score plot (Fig. 3A), indicating that different onset times of DM caused metabolic alterations. A subsequent examination focused only on the first year, where the two groups had not developed DM, yet. A Manhattan plot and HCA were used to detect significant metabolites based on which the two groups could be distinguished.

The comparison was significantly different with an FDR of $\mathrm{q}=0.05$. The FDR is a multiple testing correction applied in a statistical comparison to decrease the occurrences of false positives. The plot provides a visual presentation of the statistical test result with the application of multiple testing corrections. The $\mathrm{x}$-axis displays the $\mathrm{m} / \mathrm{z}$ values with a range of $50-1,000$, while the $y$-axis displays the $-\log \mathrm{P}$ values. The FDR criteria were indicated by the dashed lines. Features above the line (green dots) are considered to be significant between each of the two-way comparisons (samples and metabolites in HCA). Among a total of 3,462 features, the two-way comparison between the first year of ${ }^{\mathrm{G} 3} \mathrm{NND}$ and ${ }^{\mathrm{G} 4} \mathrm{NDD}$ revealed 183 to be statistically significant (Fig. 3B). 
A

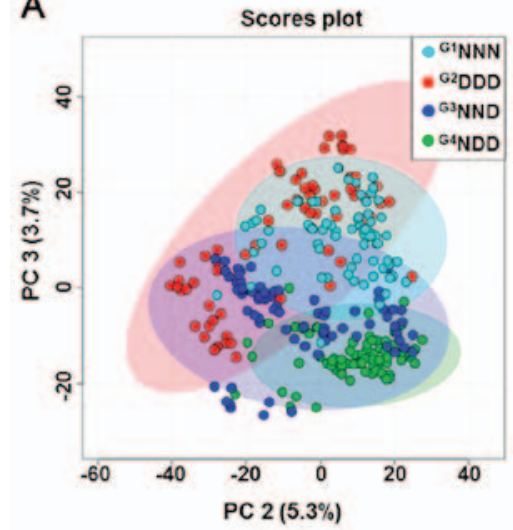

B

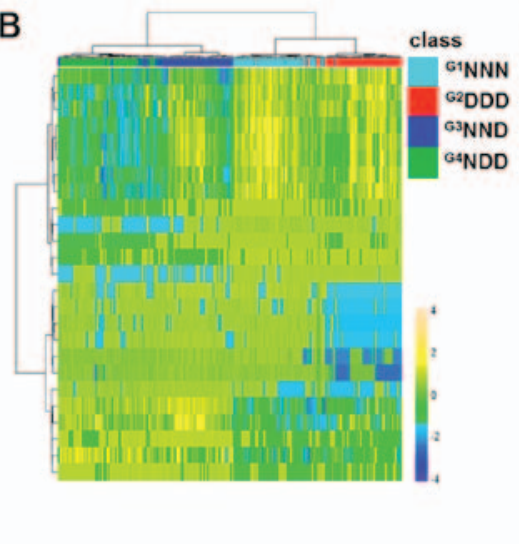

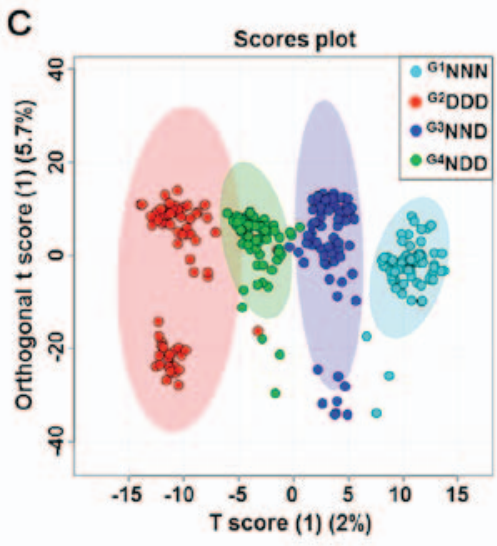

Figure 2. Multivariate statistical analyses to visualize the separation of groups. (A) PC analysis; (B) hierarchical cluster analysis and (C) orthogonal partial least-square discriminant analysis score plot $\left(\mathrm{R}^{2}=0.956, \mathrm{Q}^{2}=0.835\right)$. Groups: ${ }^{\mathrm{Gl}} \mathrm{NNN}$, control group (patients without $\left.\mathrm{DM}\right)$; ${ }^{\mathrm{G}} \mathrm{DDD}$, patients with $\mathrm{DM}$ from the beginning of study; ${ }^{\mathrm{G}} \mathrm{NND}$, patients that progressed to DM at the third year; ${ }^{\mathrm{G} 4} \mathrm{NDD}$, patients that progressed to DM at the second year. PC, principal component; DM, diabetes mellitus.

A

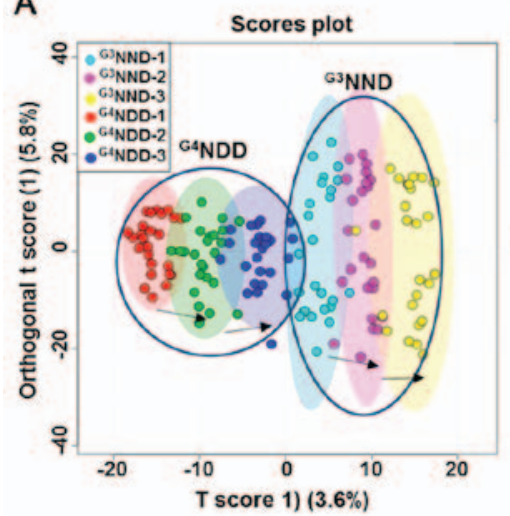

B

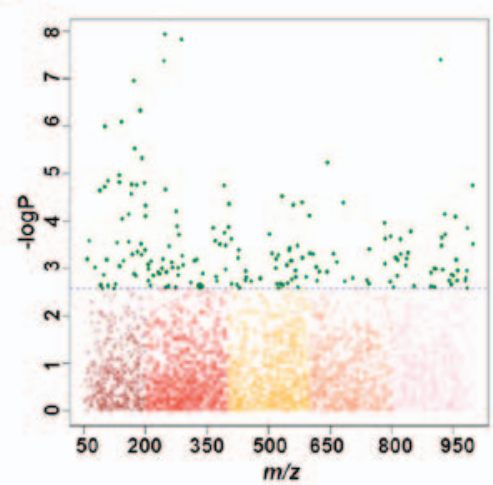

C

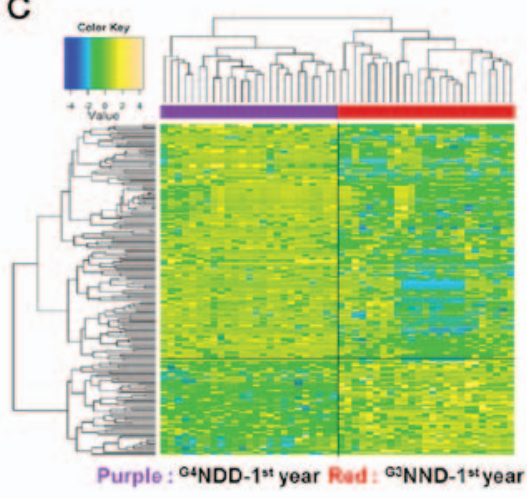

Figure 3. Determination of the mode of onset of DM from a non-diabetic status between ${ }^{\mathrm{G} 3} \mathrm{NND}$ and ${ }^{\mathrm{G} 4} \mathrm{NDD}$. (A) Orthogonal partial least-square discriminant analysis score plot $\left(\mathrm{R}^{2}=0.97, \mathrm{Q}^{2}=0.73\right)$ between ${ }^{\mathrm{G} 3} \mathrm{NND}$ and ${ }^{\mathrm{G} 4} \mathrm{NDD}$. (B) Manhattan plot. The green dots above the dashed line represent significant metabolites with a false discovery rate adjusted P-value of $<0.05$. (C) A 2-way hierarchical cluster analysis of substances with significantly altered levels considering the false discovery rate. Groups: ${ }^{\mathrm{G} 3} \mathrm{NND}$, patients that progressed to DM at the third year; ${ }^{\mathrm{G} 4} \mathrm{NDD}$, patients that progressed to DM at the second year. DM, diabetes mellitus; $\mathrm{m} / \mathrm{z}$, mass-to-charge ratio.

A two-way HCA of the comparisons' significant features indicated a clear separation of one group from the other, as displayed by the upper bar (Fig. 3C). The top label indicates the separation distance among samples and the left-hand labels indicate the clustering among metabolites, which statistically differentiated between the two groups.

The significant features were annotated using the METLIN database and mapped on the KEGG human metabolic pathways. Upon mapping the 183 significant features, 34 were matched to human metabolic pathways. Among the possible affected pathways, the two of greatest interest were the primary bile acid biosynthesis and steroid biosynthesis metabolism pathways (data not shown). Additional analyses for the second and third year of ${ }^{\mathrm{G} 3} \mathrm{NND}$ and ${ }^{\mathrm{G} 4} \mathrm{NDD}$ were performed to observe the profiles of the significant metabolites. Among the 183 significant features in the first year, 80 features remained significant in the second year and 90 features were significant in the third year.

Identification of potential biomarkers to distinguish between ${ }^{G 3} N N D$ and ${ }^{G 4} N D D$. Endogenous compounds were identified and annotated from the affected pathways (Table II). From the primary bile acid biosynthesis pathway, cholesterol, 25 -hydroxycholesterol and $3 \alpha, 7 \alpha$-dihydroxy- $5 \beta$-cholestane in the ${ }^{\mathrm{G} 3} \mathrm{NND}$-first year group were significantly different $(\mathrm{P}<0.05)$ from those of the ${ }^{\mathrm{G} 4} \mathrm{NDD}$-first year group, even though patients in the two groups were NDM at the time. Similarly, in the steroid biosynthesis pathway, cholesterol, 24,25-dihydrolanosterol and $4 \alpha$-methylzymosterol-4-carboxylate were significantly altered in the ${ }^{\mathrm{G} 3} \mathrm{NND}$-first year group compared with those in the ${ }^{\mathrm{G} 4} \mathrm{NDD}$-first year group prior to development of DM $(\mathrm{P}<0.05)$ (Figs. 4 and 5). These results indicated that only cholesterol $\left[\mathrm{m} / \mathrm{z} 369.35,\left(\mathrm{M}+\mathrm{H}-\mathrm{H}_{2} \mathrm{O}\right)^{+}\right]$affected the two pathways. However, when NDM progressed to DM, cholesterol and $4 \alpha$-methylzymosterol-4-carboxylate $[\mathrm{m} / \mathrm{z} 425.34$, $\left.\left(\mathrm{M}+\mathrm{H}-\mathrm{H}_{2} \mathrm{O}\right)^{+}\right]$were not significantly different in the second and third year $(\mathrm{P}<0.05)$. In the second year, 25-hydroxycholesterol $\left[\mathrm{m} / \mathrm{z} 403.36,(\mathrm{M}+\mathrm{H})^{+}\right]$and $3 \alpha, 7 \alpha$-dihydroxy-5 $\beta$-cholestane $\left[\mathrm{m} / \mathrm{z} 443.33,(\mathrm{M}+\mathrm{K})^{+}\right]$were still significantly altered $(\mathrm{P}<0.05)$. 24,25-Dihydrolanosterol $\left[\mathrm{m} / \mathrm{z} 429.40,(\mathrm{M}+\mathrm{H})^{+}\right]$was significantly decreased $(\mathrm{P}<0.05)$ throughout the 3 -year time course (first, second and third year) (Figs. 6 and 7). 
Table II. Significant compounds associated with the two affected pathways.

\begin{tabular}{|c|c|c|c|}
\hline Pathway/compound & $\mathrm{m} / \mathrm{z}$ & Adduct & P-value \\
\hline \multicolumn{4}{|l|}{ Primary bile acid biosynthesis } \\
\hline Cholesterol & 369.3507 & $\left(\mathrm{M}+\mathrm{H}-\mathrm{H}_{2} \mathrm{O}\right)^{+}$ & $2.62 \times 10^{-4}$ \\
\hline 25-Hydroxycholesterol & 403.3593 & $(\mathrm{M}+\mathrm{H})^{+}$ & $4.40 \times 10^{-5}$ \\
\hline $3 \alpha, 7 \alpha$-Dihydroxy- $5 \beta$-cholestane & 443.3325 & $(\mathrm{M}+\mathrm{K})^{+}$ & $1.77 \times 10^{-3}$ \\
\hline \multicolumn{4}{|l|}{ Steroid biosynthesis } \\
\hline Cholesterol & 369.3507 & $\left(\mathrm{M}+\mathrm{H}-\mathrm{H}_{2} \mathrm{O}\right)^{+}$ & $2.62 \times 10^{-4}$ \\
\hline 24,25-Dihydrolanosterol & 429.4042 & $(\mathrm{M}+\mathrm{H})^{+}$ & $2.57 \times 10^{-3}$ \\
\hline $4 \alpha$-Methylzymosterol-4-carboxylate & 425.3428 & $\left(\mathrm{M}+\mathrm{H}-\mathrm{H}_{2} \mathrm{O}\right)^{+}$ & $6.08 \times 10^{-4}$ \\
\hline
\end{tabular}

$\mathrm{m} / \mathrm{z}$, mass-to-charge ratio.

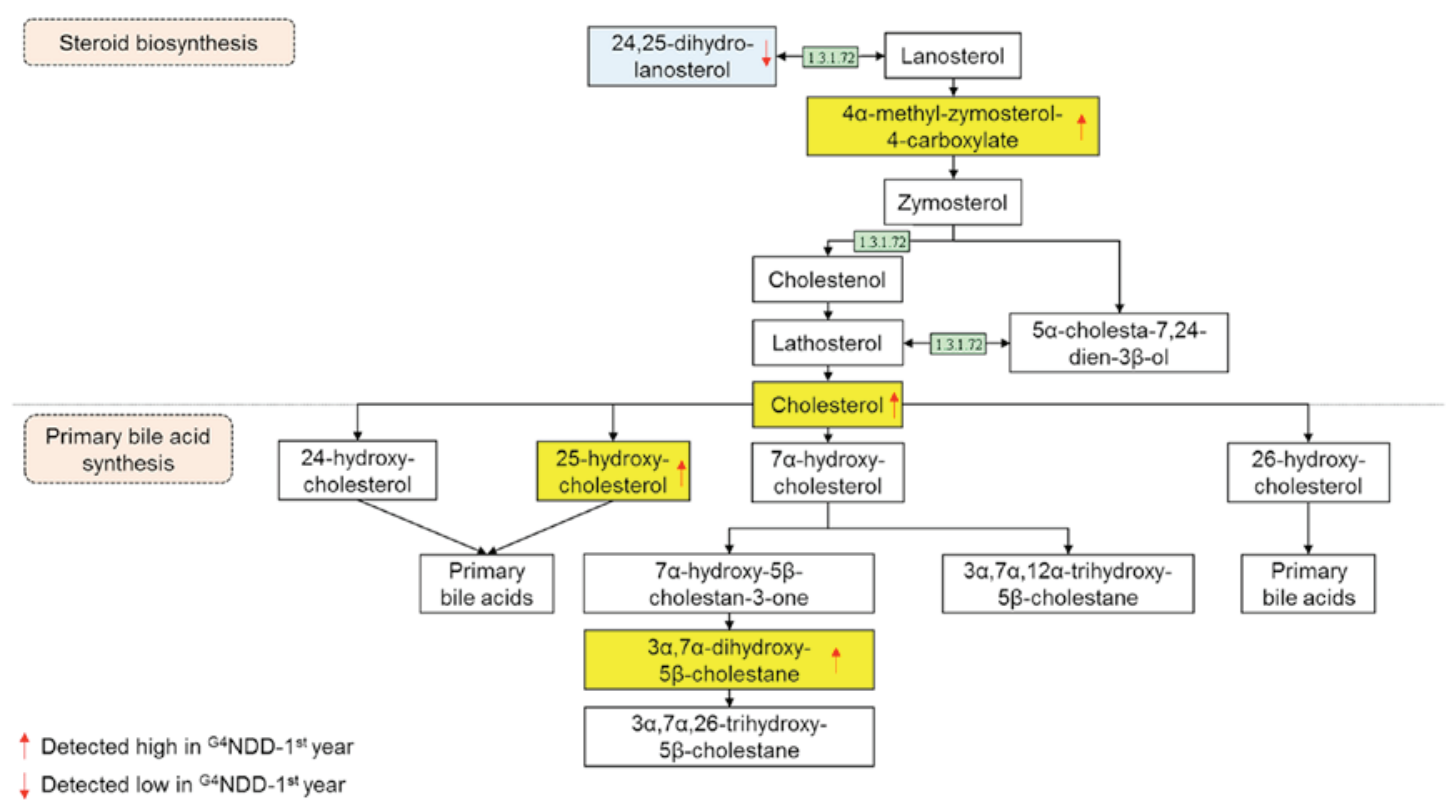

Figure 4. Steroid biosynthesis and primary bile acid biosynthesis pathway identified as key pathways affecting the progression to DM from a non-diabetic status. Green boxes indicate the 24-dehydrocholesterol reductase enzyme, regulated by 24-dehydrocholesterol reductase. Yellow boxes indicate the increase in concentration. The blue box indicates a decrease in concentration. ${ }^{\mathrm{G} 4} \mathrm{NDD}$, patients that progressed to DM at the second year. DM, diabetes mellitus.
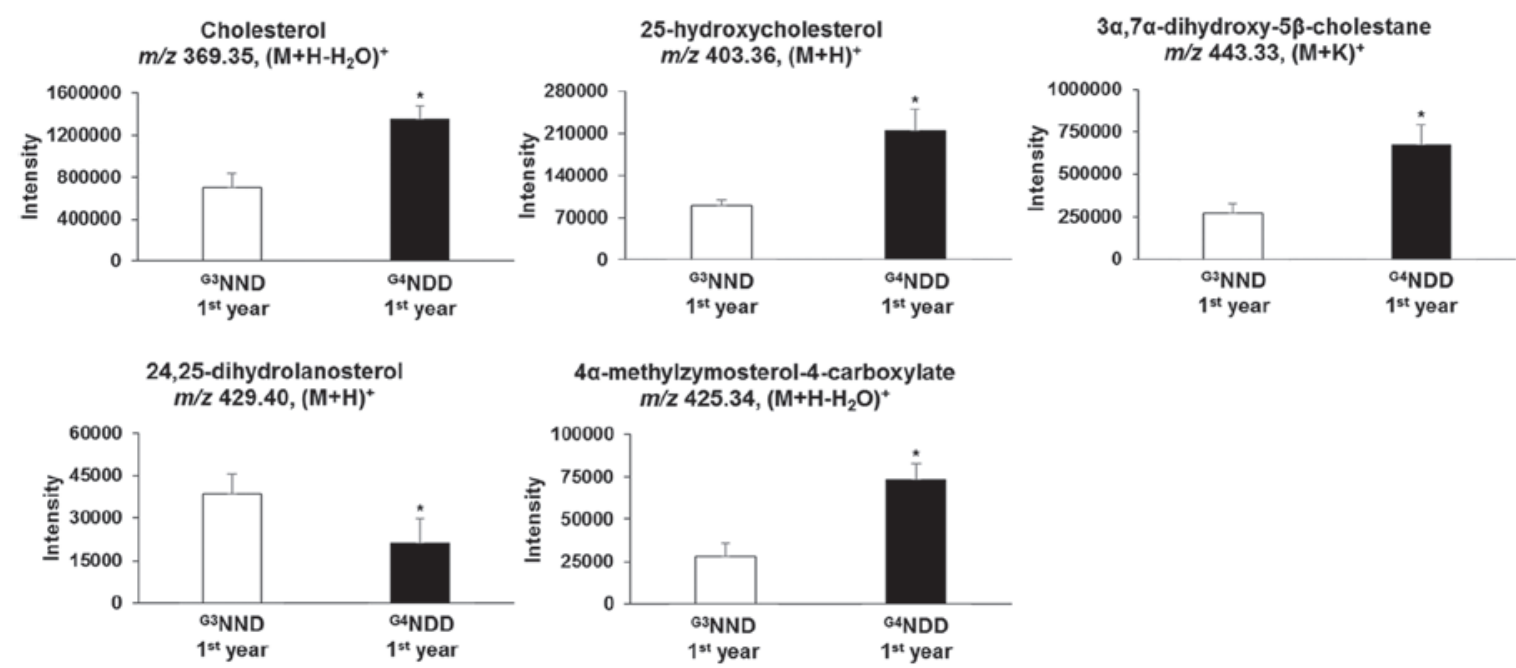

Figure 5. Significant metabolites altered in the first year between ${ }^{\mathrm{G} 3} \mathrm{NND}$ and ${ }^{\mathrm{G} 4} \mathrm{NDD} .{ }^{*} \mathrm{P}<0.05$. ${ }^{\mathrm{G} 3} \mathrm{NND}$, patients that progressed to DM at the third year; ${ }^{\mathrm{G} 4} \mathrm{NDD}$, patients that progressed to DM at the second year. DM, diabetes mellitus; $\mathrm{m} / \mathrm{z}$, mass-to-charge ratio. 

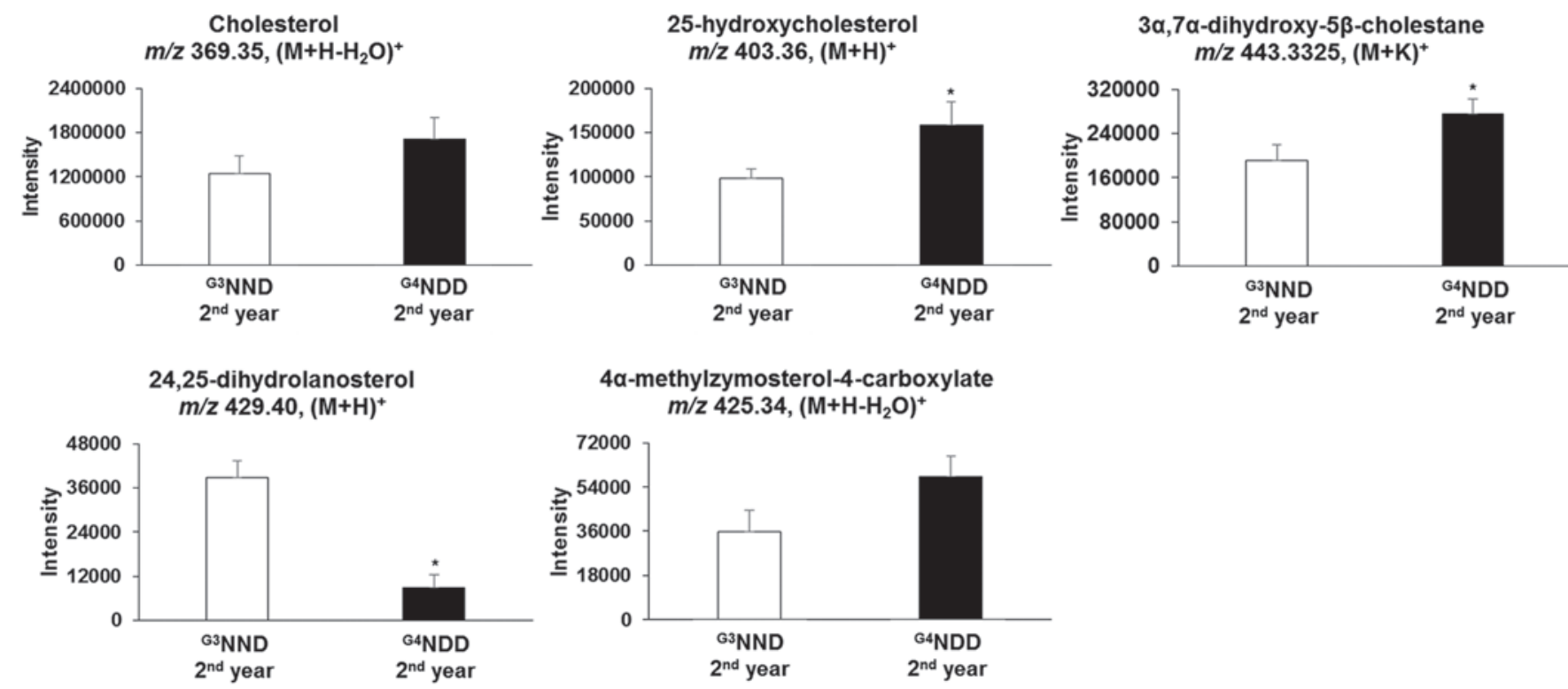

Figure 6. Intensity of the significant metabolites compared between ${ }^{\mathrm{G} 3} \mathrm{NND}$ and ${ }^{\mathrm{G} 4} \mathrm{NDD}$ in the second year. ${ }^{*} \mathrm{P}<0.05 .{ }^{\mathrm{G} 3} \mathrm{NND}$, patients that progressed to DM at the third year; ${ }^{\mathrm{G} 4} \mathrm{NDD}$, patients that progressed to DM at the second year. DM, diabetes mellitus; $\mathrm{m} / \mathrm{z}$, mass-to-charge ratio.
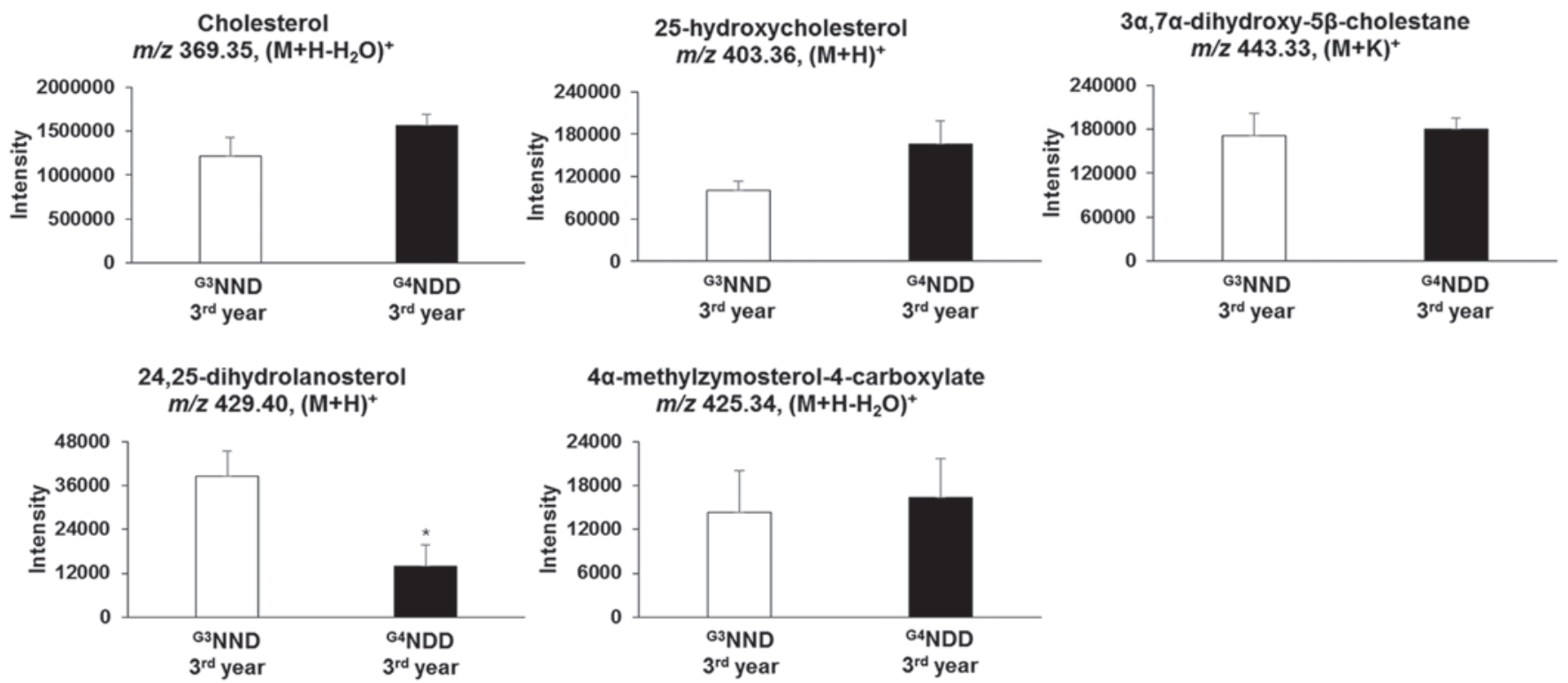

Figure 7. Intensity of the significant metabolites compared between ${ }^{\mathrm{G} 3} \mathrm{NND}$ and ${ }^{\mathrm{G} 4} \mathrm{NDD}$ at the third year. ${ }^{*} \mathrm{P}<0.05 .{ }^{\mathrm{G}} \mathrm{NND}$, patients that progressed to DM at the third year; ${ }^{\mathrm{G} 4} \mathrm{NDD}$, patients that progressed to DM at the second year. DM, diabetes mellitus; $\mathrm{m} / \mathrm{z}$, mass-to-charge ratio.

Validation of cholesterol was performed by selected reaction monitoring by detecting specific precursor-product ion transition using tandem MS mode and comparing the fragmentation pattern to its chemical standard, when available. Cholesterol ion fragmentation was detected: $\mathrm{m} / \mathrm{z} 369.35 \rightarrow \mathrm{m} / \mathrm{z}$ 147.11, m/z 161.13 and m/z 95.08 (Fig. 8).

\section{Discussion}

The present study explored metabolic profiling by comparing the mode of onset of type $2 \mathrm{DM}$ in a 3-year prospective cohort study. The results indicated the dysregulation of certain pathways and metabolites prior to the development of DM.
The baseline value of fasting blood sugar in the ${ }^{\text {G3 NND-first }}$ year and ${ }^{\mathrm{G} 4} \mathrm{NDD}$-first year groups indicated that the values in subjects who had not yet developed DM were significantly different from those who had diabetes in the ${ }^{\text {G2 }}$ DDD group. In addition, five $\mathrm{m} / \mathrm{z}$ values, which were mainly assigned to sterol compounds, exhibited statistical significance regarding the mode of onset $(\mathrm{P}<0.05)$.

The results indicate that the primary bile acid biosynthesis pathway was affected by the time of onset of DM (1 or 2 years prior to DM). Certain metabolites of the primary bile acid pathway tended to be higher in the ${ }^{\mathrm{G} 4} \mathrm{NDD}$ group-first year compared with those in the ${ }^{\mathrm{G} 3} \mathrm{NND}$ group-first year, such that 25 -hydroxycholesterol and $3 \alpha, 7 \alpha$-dihydroxy-5 $\beta$-cholestane 

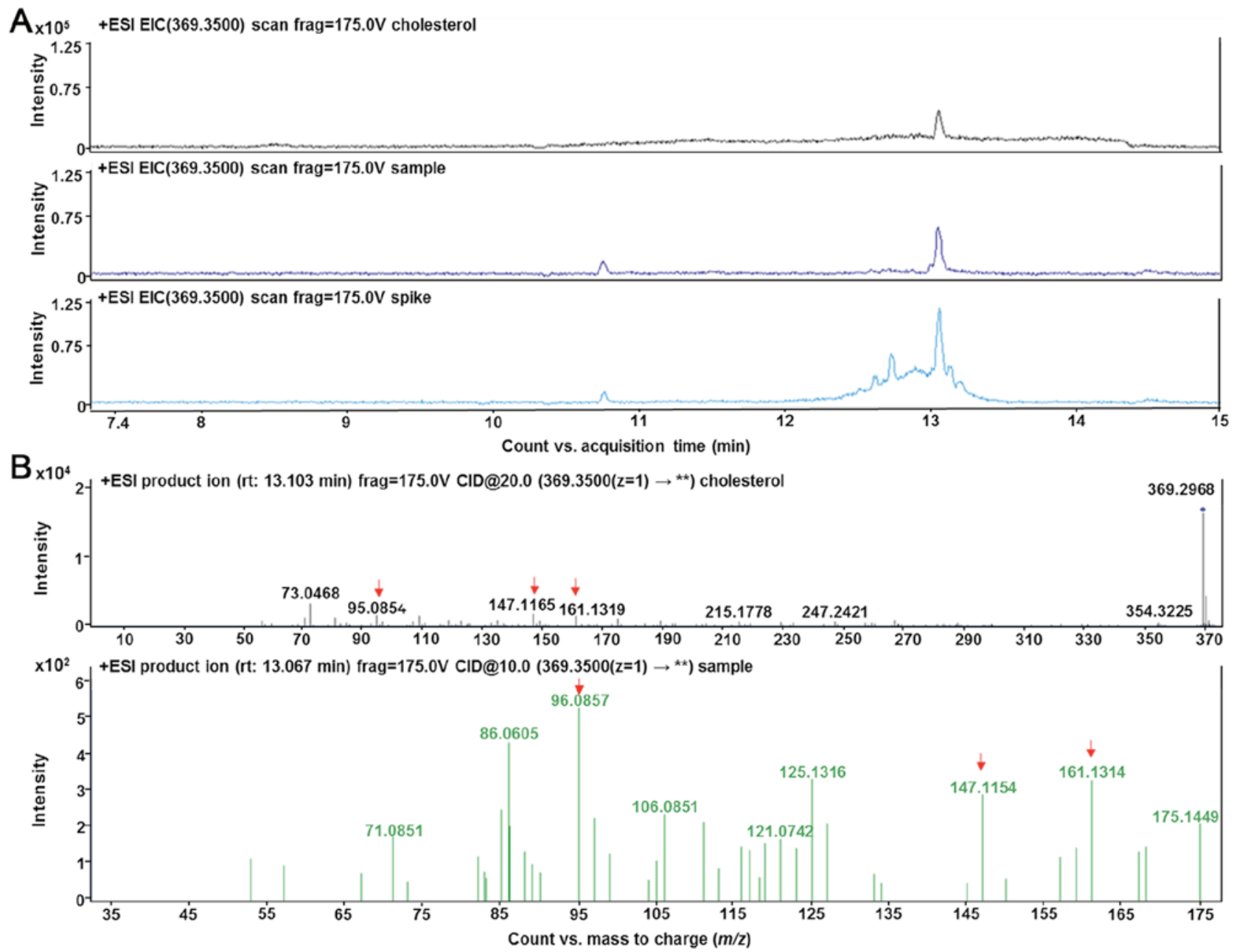

Figure 8. Identification and validation of cholesterol. (A) EIC of standard, serum and spike sample. (B) The spike peak of cholesterol was increased at 13 min The cholesterol fragmentation was observed from standard and sample with collision energy of 20 and $10 \mathrm{~V}$. The red arrows represent the fragmented cholesterol from the standard and sample. ESI, electron spray ionization; CID, collision-induced dissociation; EIC, extracted ion chromatogram; rt, retention time; frag, fragmentor voltage.

were elevated. This was in agreement with other studies reporting that bile acid synthesis was stimulated in association with DM, obesity and insulin signaling (29-31). The intensity of cholesterol, which is the precursor of bile acid biosynthesis, was elevated.

Cholesterol is a fundamental raw material for the cell. It acts as the building block for the cell membrane and other organelles (32). It serves as a precursor of numerous biosynthetic processes in human metabolic pathways, including steroid hormone and bile acid biosynthesis (33). Fig. 4 (adapted from the KEGG database) depicts the central function of cholesterol as a bridge connecting the two pathways.

In the present study, cholesterol was significantly higher in the ${ }^{\mathrm{G} 4} \mathrm{NDD}$ group-first year, in comparison with that in the ${ }^{63} \mathrm{NND}$ group-first year $(\mathrm{P}<0.05)$. This result indicated that cholesterol biosynthesis is modulated by DM progression. Fig. 4 presents part of the steroid biosynthesis pathway involving the generation of cholesterol, which stimulates primary bile acid synthesis in the ${ }^{\mathrm{G} 4} \mathrm{NDD}$ group-first year. In the present study, cholesterol production in the ${ }^{\mathrm{G} 4} \mathrm{NDD}$ group tended to be higher than that in the ${ }^{\mathrm{G} 3} \mathrm{NND}$ group, and the metabolite $4 \alpha$-methylzymosterol-4-carboxylate was also elevated in the first year. In addition, 24,25-dihydrolanosterol was lower, explaining for the boost in cholesterol production. Of note, differences in this metabolite were significant in the first, second and third years $(\mathrm{P}<0.05)$.

This upregulated downstream effect of cholesterol production may be due to the activity of one enzyme, $\delta 24$-sterol reductase (enzyme ID 1.3.1.72, also known as 24-dehydrocholesterol reductase). This enzyme participates in numerous processes and is regulated by the DHCR 24 gene $(34,35)$. This gene may be linked to diabetes progression. Berisha et al (36) indicated that DHCR24 is one of the transcripts affected by bariatric surgery in obese DM patients, with enzyme activity being correlated with changes of body weight, fasting plasma glucose and glycosylated hemoglobin content. Although focusing on endometrial carcinoma, another study revealed that the enzyme encoded by DHCR24 was induced by insulin stimulation via signal transducer and activator of transcription 3, which sensitizes to insulin signaling $(37,38)$. This mechanism is possibly associated with the pathology of diabetes due to its link with hyperinsulinemia $(39,40)$. Thus, these results indicated that the dysregulation of the metabolism, at the genomics to metabolomics level, had started to develop one year prior to the onset of DM. Cholesterol detected in the present LC-MS analysis was different from that determined 
by routine biochemical analysis, since the latter was the total cholesterol value comprising triglyceride, low-density lipoprotein (LDL) and high-density lipoprotein (HDL) values. In addition, the adduct of cholesterol, $\left(\mathrm{M}+\mathrm{H}-\mathrm{H}_{2} \mathrm{O}\right)^{+}$, had an $\mathrm{m} / \mathrm{z}$ of 369.35 in the present study, while lipoproteins of LDL and HDL containing cholesterol have different $\mathrm{m} / \mathrm{z}$ values (41).

The present study aimed to utilize HRM to further assess the mode of onset of DM. Primary bile acid biosynthesis and steroid biosynthesis metabolism, which focus on cholesterol biosynthesis, have important roles in different modes prior to the onset of DM. A future study on a larger population should be performed to validate the clinical value of the present results.

\section{Acknowledgements}

The authors would like to thank Dr Karan Uppal from Emory University School of Medicine (Atlanta, GA, USA) for providing the R-package to run the Metabolomics Wide Association Study. ADP gratefully acknowledges the Indonesia Endowment Fund for Education (grant no. A-3468/LPDP.3/2015) for the financial support of his master degree program. This study was supported by the Korea Health Industry Development Institute (grant no. HI14C2686) and the National Foundation of Korea (grant nos. NRF-2017R1A2B4003890 and NRF-2017M3A9F1031229).

\section{References}

1. American Diabetes Association: Diagnosis and classification of diabetes mellitus. Diabetes Care 28 (Suppl 1): S37-S42, 2005.

2. Flier JS, Underhill LH, Polonsky KS, Sturis J and Bell GI: Non-insulin-dependent diabetes mellitus-A genetically programmed failure of the beta cell to compensate for insulin resistance. N Engl J Med 334: 777-783, 1996.

3. Whiting DR, Guariguata L, Weil C and Shaw J: IDF diabetes atlas: Global estimates of the prevalence of diabetes for 2011 and 2030. Diabetes Res Clin Pract 94: 311-321, 2011.

4. Ling C and Groop L: Epigenetics: A molecular link between environmental factors and type 2 diabetes. Diabetes 58: 2718-2725, 2009.

5. Mahajan A, Go MJ, Zhang W, Below JE, Gaulton KJ, Ferreira T, Horikoshi M, Johnson AD, Ng MC, Prokopenko I, et al; DIAbetes Genetics Replication And Meta-analysis (DIAGRAM) Consortium; Asian Genetic Epidemiology Network Type 2 Diabetes (AGEN-T2D) Consortium; South Asian Type 2 Diabetes (SAT2D) Consortium; Mexican American Type 2 Diabetes (MAT2D) Consortium; Type 2 Diabetes Genetic Exploration by Nex-generation sequencing in muylti-Ethnic Samples (T2D-GENES) Consortium: Genome-wide trans-ancestry metaanalysis provides insight into the genetic architecture of type 2 diabetes susceptibility. Nat Genet 46: 234-244, 2014.

6. Voight BF, Scott LJ, Steinthorsdottir V, Morris AP, Dina C, Welch RP, Zeggini E, Huth C, Aulchenko YS, Thorleifsson G, et al; MAGIC investigators; GIANT Consortium: Twelve type 2 diabetes susceptibility loci identified through large-scale association analysis. Nat Genet 42: 579-589, 2010.

7. Ferrannini E, Nannipieri M, Williams K, Gonzales C, Haffner SM and Stern MP: Mode of onset of type 2 diabetes from normal or impaired glucose tolerance. Diabetes 53: 160-165, 2004.

8. Zhou K, Donnelly LA, Morris AD, Franks PW, Jennison C, Palmer CN and Pearson ER: Clinical and genetic determinants of progression of type 2 diabetes: A DIRECT study. Diabetes Care 37: 718-724, 2014.

9. Mamas M, Dunn WB, Neyses L and Goodacre R: The role of metabolites and metabolomics in clinically applicable biomarkers of disease. Arch Toxicol 85: 5-17, 2011.

10. Kaddurah-Daouk R, Kristal BS and Weinshilboum RM: Metabolomics: A global biochemical approach to drug response and disease. Annu Rev Pharmacol Toxicol 48: 653-683, 2008.
11. Wilson ID, Nicholson JK, Castro-Perez J, Granger JH, Johnson KA, Smith BW and Plumb RS: High resolution 'ultra performance' liquid chromatography coupled to oa-TOF mass spectrometry as a tool for differential metabolic pathway profiling in functional genomic studies. J Proteome Res 4: 591-598, 2005.

12. Guo K, Bamforth F and Li L: Qualitative metabolome analysis of human cerebrospinal fluid by $13 \mathrm{C}$-/12C-isotope dansylation labeling combined with liquid chromatography Fourier transform ion cyclotron resonance mass spectrometry. J Am Soc Mass Spectrom 22: 339-347, 2011.

13. Nicholson JK and Lindon JC: Systems biology: Metabonomics. Nature 455: 1054-1056, 2008.

14. Lee Y, Khan A, Hong S, Jee SH and Park YH: A metabolomic study on high-risk stroke patients determines low levels of serum lysine metabolites: A retrospective cohort study. Mol Biosyst 13: 1109-1120, 2017.

15. Kanehisa M and Goto S: KEGG: Kyoto encyclopedia of genes and genomes. Nucleic Acids Res 28: 27-30, 2000.

16. Suhre K: Metabolic profiling in diabetes. J Endocrinol 221: R75-R85, 2014.

17. Newgard CB, An J, Bain JR, Muehlbauer MJ, Stevens RD, Lien LF, Haqq AM, Shah SH, Arlotto M, Slentz CA, et al: A branched-chain amino acid-related metabolic signature that differentiates obese and lean humans and contributes to insulin resistance. Cell Metab 9: 311-326, 2009.

18. Wang TJ, Larson MG, Vasan RS, Cheng S, Rhee EP, McCabe E, Lewis GD, Fox CS, Jacques PF, Fernandez C, et al: Metabolite profiles and the risk of developing diabetes. Nat Med 17: 448-453, 2011.

19. Wang-Sattler R, Yu Z, Herder C, Messias AC, Floegel A, He Y, Heim K, Campillos M, Holzapfel C, Thorand B, et al: Novel biomarkers for pre-diabetes identified by metabolomics. Mol Syst Biol 8: 615, 2012.

20. Cheng S, Rhee EP, Larson MG, Lewis GD, McCabe EL, Shen D, Palma MJ, Roberts LD, Dejam A, Souza AL, et al: Metabolite profiling identifies pathways associated with metabolic risk in humans. Circulation 125: 2222-2231, 2012.

21. Drogan D, Dunn WB, Lin W, Buijsse B, Schulze MB, Langenberg C, Brown M, Floegel A, Dietrich S, Rolandsson O, et al: Untargeted metabolic profiling identifies altered serum metabolites of type 2 diabetes mellitus in a prospective, nested case control study. Clin Chem 61: 487-497, 2015.

22. Anjana RM, Shanthi Rani CS, Deepa M, Pradeepa R, Sudha V, Divya Nair H, Lakshmipriya N, Subhashini S, Binu VS, Unnikrishnan $\mathrm{R}$, et al: Incidence of diabetes and prediabetes and predictors of progression among Asian Indians: 10-Year follow-up of the Chennai Urban Rural Epidemiology Study (CURES). Diabetes Care 38: 1441-1448, 2015.

23. Jee SH, Batty GD, Jang Y, Oh DJ, Oh BH, Lee SH, Park SW, Seung KB, Kimm H, Kim SY, et al: The Korean Heart Study: Rationale, objectives, protocol, and preliminary results for a new prospective cohort study of 430,920 men and women. Eur J Prev Cardiol 21: 1484-1492, 2014

24. Want EJ, O'Maille G, Smith CA, Brandon TR, Uritboonthai W, Qin C, Trauger SA and Siuzdak G: Solvent-dependent metabolite distribution, clustering, and protein extraction for serum profiling with mass spectrometry. Anal Chem 78: 743-752, 2006.

25. Yu T, Park Y, Johnson JM and Jones DP: apLCMS - adaptive processing of high-resolution LC/MS data. Bioinformatics 25: 1930-1936, 2009.

26. Benjamini Y and Hochberg Y: Controlling the false discovery rate: A practical and powerful approach to multiple testing. JR Stat Soc B B57: 289-300, 1995.

27. Ritchie ME, Phipson B, Wu D, Hu Y, Law CW, Shi W and Smyth GK: limma powers differential expression analyses for RNA-sequencing and microarray studies. Nucleic Acids Res 43: e47, 2015.

28. Smith CA, O'Maille G, Want EJ, Qin C, Trauger SA, Brandon TR, Custodio DE, Abagyan R and Siuzdak G: METLIN: A metabolite mass spectral database. Ther Drug Monit 27: 747-751, 2005.

29. Prawitt J, Caron S and Staels B: Bile acid metabolism and the pathogenesis of type 2 diabetes. Curr Diab Rep 11: 160-166, 2011.

30. Li T, Francl JM, Boehme S, Ochoa A, Zhang Y, Klaassen CD, Erickson SK and Chiang JY: Glucose and insulin induction of bile acid synthesis: Mechanisms and implication in diabetes and obesity. J Biol Chem 287: 1861-1873, 2012.

31. Tomkin GH and Owens D: Obesity diabetes and the role of bile acids in metabolism. J Transl Int Med 4: 73-80, 2016.

32. Russell DW: Cholesterol biosynthesis and metabolism. Cardiovasc Drugs Ther 6: 103-110, 1992. 
33. Simons $\mathrm{K}$ and Ikonen E: How cells handle cholesterol. Science 290: 1721-1726, 2000.

34. Fernández C, Suárez Y, Ferruelo AJ, Gómez-Coronado D and Lasunción MA: Inhibition of cholesterol biosynthesis by Delta22-unsaturated phytosterols via competitive inhibition of sterol Delta24-reductase in mammalian cells. Biochem J 366: 109-119, 2002.

35. Luu W, Zerenturk EJ, Kristiana I, Bucknall MP, Sharpe LJ and Brown AJ: Signaling regulates activity of DHCR24, the final enzyme in cholesterol synthesis. J Lipid Res 55: 410-420, 2014.

36. Berisha SZ, Serre D, Schauer P, Kashyap SR and Smith JD Changes in whole blood gene expression in obese subjects with type 2 diabetes following bariatric surgery: A pilot study. PLoS One 6: e16729, 2011

37. Dai M, Zhu XL, Liu F, Xu QY, Ge QL, Jiang SH, Yang XM, Li J, Wang YH, Wu QK, et al: Cholesterol synthetase DHCR24 induced by insulin aggravates cancer invasion and progesterone resistance in endometrial carcinoma. Sci Rep 7: 41404, 2017.
38. Moh A, Zhang W, Yu S, Wang J, Xu X, Li J and Fu XY: STAT3 sensitizes insulin signaling by negatively regulating glycogen synthase kinase-3 beta. Diabetes 57: 1227-1235, 2008

39. Weyer C, Bogardus C, Mott DM and Pratley RE: The natural history of insulin secretory dysfunction and insulin resistance in the pathogenesis of type 2 diabetes mellitus. J Clin Invest 104: 787-794, 1999.

40. Weyer C, Funahashi T, Tanaka S, Hotta K, Matsuzawa Y, Pratley RE and Tataranni PA: Hypoadiponectinemia in obesity and type 2 diabetes: Close association with insulin resistance and hyperinsulinemia. J Clin Endocrinol Metab 86: 1930-1935, 2001.

41. Schiller J, Zschörnig O, Petković M, Müller M, Arnhold J and Arnold K: Lipid analysis of human HDL and LDL by MALDI-TOF mass spectrometry and (31)P-NMR. J Lipid Res 42: 1501-1508, 2001. 